\title{
Prevalence of childhood obesity and its determinants among rural children of B G Nagara
}

\author{
Asharani N1,*, Rahul H V ${ }^{2}$, Aliya Nusrath ${ }^{3}$ \\ ${ }^{\mathbf{1}}$ Associate Professor, ${ }^{2}$ Medical Student, ${ }^{3}$ Professor and Head, Dept. of Biochemistry, Adichunchanagiri Institute of Medical \\ Sciences, B G Nagara, Karnataka, India \\ *Corresponding Author: Asharani N \\ Email: ashanellore@gmail.com
}

Received: $22^{\text {nd }}$ February, 2018

Accepted: $1^{\text {st }}$ July, 2018

\begin{abstract}
Introduction: India is witnessing under nutrition as one of the major public health problem, however there exists a significant magnitude of overweight and obesity among children and adolescent. Childhood obesity has emerged as one of the global health problems as a result of high intake of calorie rich foods and low level of physical activity. Most of the studies are conducted at metropolitan cities with limited information on prevalence of childhood obesity in rural area.

Aim and Objective: To determine the prevalence of obesity among school children in the age group of 6-12 years in rural Mandya.

Materials and Methods: A cross sectional survey was conducted among 1328 students in the age group 6-12 years. The body mass index (BMI) for age charts were used to assess weight in relation to height as recommended by Centers for Disease Control and Prevention. The $85^{\text {th }}-95^{\text {th }}$ percentile and $\geq 95^{\text {th }}$ percentile specific for age and sex were used to define overweight and obesity respectively in children.

Results and Conclusion: Data from 1288 students were included for analysis with the overall response rate of $96.98 \%$. Out of 1288 participants $777(60.3 \%)$ were boys, 511 (39.7\%) were girls. The prevalence of underweight, overweight and obesity was $54.9 \%(\mathrm{n}=707), 1.8 \%(\mathrm{n}=24)$ and about $1 \%(\mathrm{n}=12)$ respectively. The prevalence was more towards pubertal age $(10-12$ years $)$ than in early childhood. Childhood obesity was not associated with parental obesity or junk food consumption in children. To conclude, even though prevalence of childhood overweight /obesity was about $2.8 \%$, it necessitates immediate action as it is accompanied by many non-communicable diseases such as diabetes, hypertension and cardiovascular disease.
\end{abstract}

Keywords: Prevalence, Childhood obesity, Overweight, School children, BMI, Junk food.

\section{Introduction}

Even though, India is witnessing under nutrition as one of the major public health problem, there exists a significant magnitude of overweight and obesity among children and adolescent. Childhood obesity has emerged as one of the global health problems ${ }^{1}$ as a result of high intake of calorie rich foods, low level of physical activity ${ }^{2}$ and due to effects of genetic and environmental factors. The dramatic rise in the prevalence $^{3,4}$ of over nutrition resulting in overweight and obesity among children have been accompanied by alarming increase in non-communicable diseases such as diabetes mellitus ${ }^{5,6}$ hypertension ${ }^{7}$ and cardiovascular disease. $^{8}$

Most of the reports addressing childhood obesity are from studies conducted at metropolitan cities with limited information on prevalence of childhood obesity in rural areas. Hence the present study was designed to determine the prevalence of overweight and obesity among school children of rural area.

\section{Materials and Methods}

A cross sectional survey in a rural based school was carried out among school children aged 6 to 12 years. A total of 1328 students were included in the study. Students absent on the day of visit, suffering from chronic illness, whose exact date of birth and not willing to participate were excluded. The school authority was informed well in advance and provided all the information about the study. Consent was obtained after explaining the purpose of the study in the local language. The study was conducted in accordance to the principles of Institutional ethical committee and ethical clearance was obtained.

The questionnaire was framed in simple language so that the participants could answer them easily. It elicited the information regarding demographic details, parent's education level, number of siblings, diet pattern, physical activity, television viewing time, use of electronic gadgets, consumption of junk foods and family history of non-communicable disease such as obesity, diabetes and hypertension.

A digital weighing scale and stadiometer were used to measure weight (nearest to $0.1 \mathrm{~kg}$ ) and height (nearest to $0.5 \mathrm{~cm}$ ) respectively with bare foot, arms hanging by the sides, heels together for each study participants. The body mass index (BMI) for age charts were used to assess weight in relation to height as recommended by Centers for Disease Control and Prevention. The $85^{\text {th }}-95^{\text {th }}$ percentile and $\geq 95^{\text {th }}$ percentile specific for age and sex was used to define overweight and obesity. ${ }^{9}$ 


\section{Statistical Analysis}

The data was coded and managed in excel spread sheet. All the entries were double checked for any possible transcription error. The variables were expressed as frequency, percentage, and percentile. The study participants were categorized into normal, overweight and obesity depending on the BMI percentile cutoff values. ${ }^{9}$ Chi square test was employed to check the association between categorical variables. $P$ value less than 0.05 was considered statistically significant.

\section{Results and Discussion}

A total of 1328 students were invited to participate in the study and data from 1288 students were included for analysis. The overall response rate was $96.98 \%$ $(\mathrm{n}=1288)$. The 40 non-responders included children absent on the day of visit, not willing to participate, chronic illness and whose exact date of birth was not available. Out of 1288 participants $60.3 \%(\mathrm{n}=777)$ were boys, $39.7 \%(\mathrm{n}=511)$ were girls, parents of $72(5.6 \%)$ children were illiterate and $1019 \quad(79.1 \%)$ were graduates. Majority of the students $(61.1 \%)$ belonged to nuclear type of family. Among 1288 children, 84.9\% were on mixed type of diet, $8.6 \%$ and $17.84 \%$ of students consumed daily carbonate drinks and bakery/ fast foods respectively.

The prevalence of underweight, overweight and obesity was $54.9 \%(\mathrm{n}=707), 1.8 \%(\mathrm{n}=24)$ and about $1 \%$ $(n=12)$ respectively. $61.1 \%$ of obese children were in the pubertal age group (10-12). More than half of obese children's parents (64\%) were obese and 94\% of obese children were indulged in consumption of junk foods, but neither parental obesity nor consumption of junk foods was associated with childhood obesity.

Developing countries like India are still addressing undernutrition, however in recent years' childhood obesity has emerged as a pandemic problem. There exists a link between childhood obesity and many noncommunicable diseases such as diabetes, cardiovascular diseases, hypertension, etc. In the present cross sectional survey conducted among school children of rural area showed $1.8 \%$ and $1 \%$ prevalence of overweight and obesity respectively. Various studies conducted in different parts of India showed varied prevalence of overweight and obesity among school children. Preetham Mahajan et al, ${ }^{10}$ Premanath $\mathrm{M}$ et al ${ }^{11}$ and Sen Suchithra et al ${ }^{12}$ reported $2.12 \%, 3.4 \%$ and $13 \%$ prevalence of obesity respectively. A study by Babitha Rexlin $\mathrm{G}$ et $\mathrm{al}^{13}$ reported a prevalence of $4.3 \%$ in rural school children and $12 \%$ among school children of urban area concluding that place of residence and socioeconomic status has strong association with obesity. Easy availability of junk foods and ready to use premixes at markets and home of children belonging to urban area and high socio-economic status may be the reason for increased prevalence. ${ }^{12}$ In this study, prevalence of obesity was higher in children belonging to $10-12$ age group when compared to $6-9$ years $\left(\mathrm{x}^{2}\right.$ $=24.38, \mathrm{p}$ value is $<0.00001)$ and was statistically significant. This high prevalence could be due to the hormonal effects which are seen during pubertal age. The study also documented higher prevalence of obesity in males as compared to females, but was not statistically significant. These results are in accordance to other results reported from Punjab ${ }^{14}$ and Delhi. ${ }^{15}$ However, study by Babitha Rexlin $\mathrm{G}$ et $\mathrm{al}^{13}$ compared obesity status between gender and concluded that gender has no relation with obesity. Analysis of association between childhood obesity and obesity in parents revealed no significant influence. This result is in accordance with results reported by Babitha Rexlin G et al. ${ }^{13}$ Childhood obesity is a stronger predictor of obesity during adult life than parental obesity.

Even though, about $95 \%$ of obese children in the present study were indulged in consumption of junk foods, obesity was not associated with it. The reason could be due to low frequency of consumption of junk foods in these children and also they are involved in regular physical activity of not less than half an hour every day. Children belonging to high socioeconomic group and urban area are having high prevalence of childhood obesity ${ }^{13}$ which highlights the possible influence of life style modifications mainly pertaining to dietary pattern and physical activity. ${ }^{15}$

\section{Limitations}

This is cross sectional survey and data except anthropometric measurements are all self-reported responses based on recall.

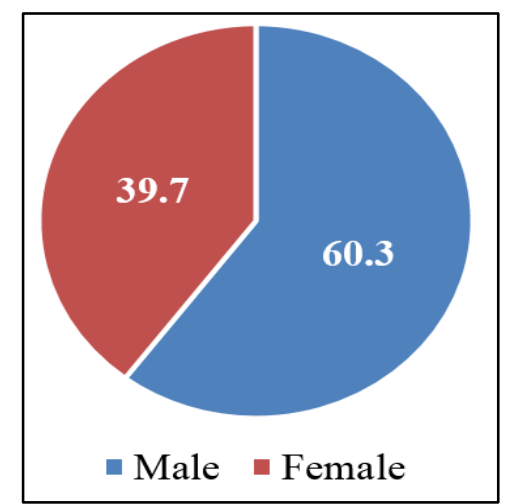

Fig. 1: Gender wise distribution (\%) of study participants

Table 1: Prevalence of underweight, overweight and obesity among study participants

\begin{tabular}{|l|c|c|}
\hline \multicolumn{1}{|c|}{ BMI Category } & Frequency & Percentage \\
\hline Under-weight & 707 & 54.9 \\
\hline Normal & 545 & 42.3 \\
\hline Overweight & 24 & 1.8 \\
\hline Obesity & 12 & 1.0 \\
\hline
\end{tabular}


Table 2: Age wise prevalence of obesity

\begin{tabular}{|l|c|}
\hline \multicolumn{1}{|c|}{ Age in years } & Obesity N (\%) \\
\hline 6 & $6(16.67)$ \\
\hline 7 & $1(2.78)$ \\
\hline 8 & $3(8.33)$ \\
\hline 9 & $4(11.11)$ \\
\hline 10 & $9(25)$ \\
\hline 11 & $7(19.44)$ \\
\hline 12 & $6(16.67)$ \\
\hline Grand Total & $36(100)$ \\
\hline
\end{tabular}

Table 3: Association of age and childhood obesity

\begin{tabular}{|c|c|c|c|c|}
\hline $\begin{array}{c}\text { Age group } \\
\text { (Years) }\end{array}$ & $\begin{array}{c}\text { Non-Obese } \\
\mathbf{N}(\boldsymbol{\%})\end{array}$ & $\begin{array}{c}\text { Obese } \\
\mathbf{N}(\boldsymbol{\%})\end{array}$ & $\begin{array}{c}\text { Total } \\
\mathbf{N}(\boldsymbol{\%})\end{array}$ & $\begin{array}{c}\text { P- } \\
\text { value }\end{array}$ \\
\hline $6-9$ & $144(91.1)$ & $14(8.9)$ & $158(100)$ & \multirow{2}{*}{$0.0001^{*}$} \\
\cline { 1 - 4 } $10-12$ & $1108(98.1)$ & $22(1.9)$ & $1130(100)$ & \\
\cline { 1 - 4 } Total & 1252 & 36 & 1288 & \\
\hline
\end{tabular}

*HS - Highly Significant

Table 4: Association of gender and childhood obesity

\begin{tabular}{|l|c|c|c|c|}
\hline Gender & $\begin{array}{c}\text { Non-Obese } \\
\mathbf{N}(\%)\end{array}$ & $\begin{array}{c}\text { Obese } \\
\mathbf{N}(\%)\end{array}$ & $\begin{array}{c}\text { Total } \\
\mathbf{N}(\%)\end{array}$ & \multirow{2}{*}{ P-value } \\
\hline Male & $755(97.1)$ & $22(2.9)$ & $777(100)$ & \multirow{2}{*}{$0.922^{* *}$} \\
\hline Female & $497(97.2)$ & $14(2.8)$ & $511(100)$ & \\
\hline Total & 1252 & 36 & 1288 & \\
\hline
\end{tabular}

** NS - Not significant

Table 5: Association of Parental obesity and obesity in their children

\begin{tabular}{|l|c|c|c|c|c|}
\hline $\begin{array}{c}\text { Parental } \\
\text { Obesity }\end{array}$ & $\begin{array}{c}\text { Non-Obese } \\
\text { child N(\%) }\end{array}$ & $\begin{array}{c}\text { Obese child } \\
\mathbf{N}(\boldsymbol{\%})\end{array}$ & $\begin{array}{c}\text { Total } \\
\mathbf{N}(\boldsymbol{\%})\end{array}$ & Chi square & P-value \\
\hline Present & $593(96.3)$ & $23(3.7)$ & $616(100)$ & \multirow{2}{*}{3.82} & $0.056^{* *}$ \\
\hline Not present & $659(98.1)$ & $13(1.9)$ & $672(100)$ & & \\
\hline Total & 1252 & 36 & 1288 & & \\
\hline
\end{tabular}

*NS - Not significant

Table 6: Association of consuming junk food and obesity in children

\begin{tabular}{|l|c|c|c|c|c|}
\hline $\begin{array}{c}\text { Consumption of Junk } \\
\text { food }\end{array}$ & $\begin{array}{c}\text { Non-Obese child } \\
\mathbf{N}(\boldsymbol{\%})\end{array}$ & $\begin{array}{c}\text { Obese child } \\
\mathbf{N}(\boldsymbol{\%})\end{array}$ & $\begin{array}{c}\text { Total } \\
\mathbf{N}(\boldsymbol{\%})\end{array}$ & Chi square & P-value \\
\hline Present & $1149(97.1)$ & $34(2.9)$ & $1183(100)$ & 0.33 & $0.56^{* *}$ \\
\hline Not present & $103(98.1)$ & $2(1.9)$ & $105(100)$ & & \\
\hline Total & 1252 & 36 & 1288 & & \\
\hline
\end{tabular}

**NS - Not significant

\section{Conclusion}

The prevalence of underweight was high (59.4\%) and childhood obesity was low (1\%) among study participants. This prevalence rate of childhood obesity is not at an alarming rates as seen in other reports from southern parts of India. However, it necessitates appropriate action as childhood obesity is accompanied by many non-communicable diseases such as diabetes, hypertension and cardiovascular disease.

\section{Acknowledgement}

We thank the school management, all the children who participated in the study, Mr. Gaganpreeth L, Mr. Yatheesh and Mr Shankaregowda for their support.

\section{References}

1. WHO/IASO/IOTF. Obesity the global epidemic. The Asia Pacific Perspective. Available from: URL: http://www. iaso.org/ iotf/ obesity/ obesity the global epidemic.

2. Kaushik JS, Narang M, Parakh A. Fast food consumption in children. Indian Pediatrics. 2011;48:97-101.

3. Kapil U, Singh P, Dwivedi S N. Prevalence of obesity among affluent adolescent school children. Indian pediatrics. 2001;39:449-52.

4. Chaitali G, Mangala S, Hemalatha AJ, Pradeep C, Subrahmanyam G. Childhood and Adolescent Overweight and Obesity - A Public Health Challenge in India. Int J Sci Stud. 2014;2(4):17-9. 
5. Sinha R, Fisch G, Teague B, Tamborlane WV, Banyas B, Allen K, Savoye M, Rieger V, Taksali S, Barbetta G, Sherwin RS, Caprio S. Prevalence of impaired glucose tolerance among children and adolescents with marked obesity. N Engl J Med. 2002;346:802-10.

6. Weiss R, Dzuira J, Burgert TS. Obesity and the metabolic syndrome in children and adolescents. $N$ Eng $J$ Med. 2004;350:2362-2374.

7. Saravanam M, Rangwala MT, Deepti S. Prevalence of anthropometric and blood pressure related issues in school going children from Surat city, India. Int J Health Sci Res. 2013;3(11):18-23.

8. Freedman Ds, Mei Z, Srinivasan SR, Berenson GS, Dietz WH. Cardiovascular risk factors and excess adiposity among overweight children and adolescents, the Bagalusa Heart Study. J Pediatr. 2007;150(1):12-7.

9. Centers for Disease Control and Prevention. Division of Nutrition, Physical activity and Obesity, National Center for Chronic Disease Prevention and Health Promotion. (accessed on 20-01-2017).

10. Mahajan, Preetam B. Study of childhood obesity among school children aged 6 to 12 years in union territory of Puducherry. Indian journal of community medicine: official publication of Indian Association of Preventive \& Social Medicine 2011;36(1):45.

11. M Premanath, H Basavanagowdappa, MA Shekar, SB Vikram, D Narayanappa. Mysore childhood obesity study. Indian paediatrics. 2010;47(2):171-3.
12. Sen Sucharita, Verma Renu. Relationship between childhood obesity and eating habits in school going children (6-11 years) of Central India. Indian Journal of Basic and Applied Medical Research. 2015;4(4):242-50.

13. Babitha Rexlin G, Sivakumar E, Rajkumar D, Nagendran M. Prevalence of obesity among school children in Madurai. Int J Cur Res. 2016;8(22):1-6.

14. Chhatwal J, Verma M, Riar SK. Obesity among preadolescents of a developing country (India). Asia Pac J Clin Nutr. 2004;13:231-5.

15. S Kaur, HPS Sachdev, SN Dwivedi, R Lakshmy, U Kapil. Prevalence of overweight and obesity amongst school children in Delhi, India. Asia Pac J Clin Nutr. 2008;17(4):592-6.

How to cite this article: Asharani N, Rahul
$\mathrm{H} \mathrm{V}$, Nusrath A. Prevalence of childhood
obesity and its determinants among rural
children of B G Nagara. Int J Clin Biochem
Res. 2018;5(4):509-512.

